\title{
BDDCS Predictions, Self-Correcting Aspects of BDDCS Assignments, BDDCS Assignment Corrections, and Classification for more than 175 Additional Drugs
}

\author{
Chelsea M. Hosey, ${ }^{1}$ Rosa Chan, ${ }^{1}$ and Leslie Z. Benet ${ }^{1,2}$
}

Received 9 September 2015; accepted 9 November 2015; published online 20 November 2015

\begin{abstract}
The biopharmaceutics drug disposition classification system was developed in 2005 by Wu and Benet as a tool to predict metabolizing enzyme and drug transporter effects on drug disposition. The system was modified from the biopharmaceutics classification system and classifies drugs according to their extent of metabolism and their water solubility. By 2010, Benet et al. had classified over 900 drugs. In this paper, we incorporate more than 175 drugs into the system and amend the classification of 13 drugs. We discuss current and additional applications of BDDCS, which include predicting drug-drug and endogenous substrate interactions, pharmacogenomic effects, food effects, elimination routes, central nervous system exposure, toxicity, and environmental impacts of drugs. When predictions and classes are not aligned, the system detects an error and is able to self-correct, generally indicating a problem with initial class assignment and/or measurements determining such assignments.
\end{abstract}

KEY WORDS: BDDCS; biopharmaceutics drug disposition classification system; disposition; drug development; drug transport.

\section{INTRODUCTION}

Pharmacokinetics and pharmacodynamics are mediated by drug transporters or passive processes as well as potentially drug-metabolizing enzymes. Drug transporters regulate the ability of some drugs to be absorbed from the small intestine, where some drugs may be initially metabolized. The activity and expression of transporters and metabolizing enzymes can therefore affect the bioavailability of the drug, either independently or in concert with each other (1). Drug transporters are expressed in a variety of tissues, including the liver and kidney - the organs primarily responsible for drug elimination-and target tissues such as the brain and heart. The expression and activity of drug transporters can determine the degree to which a drug can access organs, impacting on-target efficacy, off-target toxicity, or elimination. Elimination can also be influenced by the activity and expression of metabolizing enzymes, which are responsible for changing a drug into a usually more hydrophilic, watersoluble metabolite that can be more easily eliminated in the bile or urine than the parent drug. Drug transporters and metabolizing enzymes can therefore significantly impact the disposition of drugs.

Understanding the disposition of drugs is crucial during drug development. Each major dispositional process (absorption, distribution, metabolism, and elimination) impacts the

\footnotetext{
$\overline{{ }^{1} \text { Department of Bioengineering and Therapeutic Sciences, University of }}$ California, San Francisco, 533 Parnassus Ave., Room U-68, San Francisco, California 94143-0912, USA.

${ }^{2}$ To whom correspondence should be addressed. (e-mail: leslie.benet@ucsf.edu)
}

safety and efficacy of a drug. In turn, other drugs, endogenous substrates, pharmacogenomics, and food can affect each of these processes. Drug interaction studies are a critical component of clinical development. Since considering the impact of each transporter or metabolizing enzyme, which can be expressed in multiple organs, is too slow and expensive, pharmaceutical scientists have prioritized when interactions with transporters and enzymes are likely to be clinically important $(2,3)$.

Defining whether enzymes and transporters are clinically important can be further simplified by considering only two properties of the drug in question: its extent of metabolism and its solubility (Box 1). These features are straightforward to obtain. The extent of metabolism is routinely obtained during phase I clinical trials, while solubility can be measured in a laboratory (4). These two features are demarcated by high and low values, classifying drugs into four categories. These classes are each associated with specific predictions regarding which interactions may be a clinical concern. This predictive system is called the Biopharmaceutics Drug Disposition Classification System. The Biopharmaceutics Drug Disposition Classification System (BDDCS) was developed in 2005 (5) after $\mathrm{Wu}$ and Benet recognized that highly permeable compounds, as outlined by the Biopharmaceutics Classification System (BCS) developed by Amidon et al. (6), were extensively metabolized, while poorly permeable drugs were poorly metabolized. We expect that the relationship between a high permeability rate and a high extent of metabolism is a result of ready reabsorption of highly permeable drugs from the bile or the kidney lumen. Indeed, Gustafson and Benet (7) demonstrated that reabsorption of drugs from the bile is possible, while a recent study by Dave and Morris (8) found that $82 \%$ of drugs 


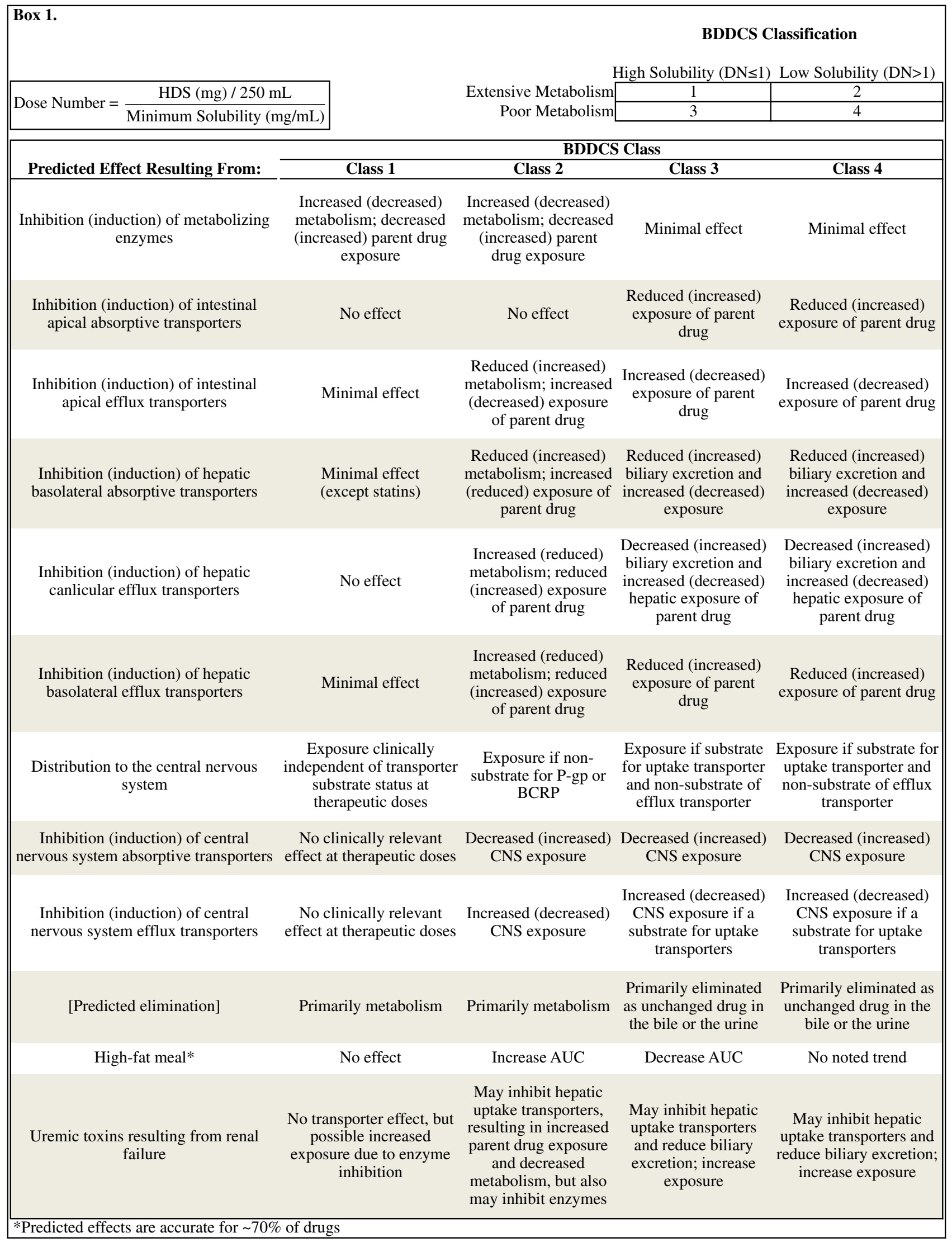


that are reabsorbed from the kidney tubule were BDDCS class 1 and 2 drugs. Analyzing a dataset published by Varma et al. (9) that included whether a drug was reabsorbed, secreted, or passively filtered by the kidneys, $52 \%$ of the class 1 and 2 compounds were reabsorbed compared to $19 \%$ of the class 3 and 4 compounds, while $69 \%$ of class 3 and 4 compounds were secreted in the tubule compared to $37 \%$ of class 1 and 2 compounds.

There is a marked distinction between extensively and poorly metabolized compounds: compounds in class 1 and 2 tend to attribute $\geq 70 \%$ of their disposition to metabolism, while classes 3 and 4 are primarily eliminated as unchanged drug and tend to attribute $\leq 30 \%$ of their elimination to metabolism, with few drugs having an intermediate extent of metabolism. Solubility is defined by FDA standards. While solubility was classified by dose number of the minimum solubility of the highest dose strength of the formulated drug at $37^{\circ} \mathrm{C}$ over the $\mathrm{pH}$ range of 1 to 7.5 initially, the $\mathrm{pH}$ range has recently been adjusted to 1 to 6.8 (10) that more accurately reflects the physiology of the gut. When the dose number $\leq 1$, the drug is considered highly soluble, and when the dose number $>1$, the drug is considered poorly soluble (4). The classification system and predictions are detailed in Box 1.

It is important to recognize that the predictions $\mathrm{Wu}$ and Benet (5) proposed with regard to BDDCS were based on observations, not theory. These observations were supported by a broad knowledge of the pharmacokinetics of drugs including major elimination route and an understanding of metabolizing enzymes and transporters and their interactions. From these observations, they proposed 22 dispositional predictions for approved drugs belonging to each class (5). $\mathrm{Wu}$ and Benet were unable to identify any clinically relevant transporter effects in the gut or the liver for the BDDCS class 1 drugs for the 153 drugs initially classified in the BDDCS. Briefly, class 1 drugs are expected to experience potentially clinically relevant dispositional changes when metabolizing enzymes are affected, but not when transporters are affected. As extensive metabolism necessitates extensive absorption, the BDDCS may be useful in granting biowaivers of some class 1 drugs, which has been implemented in EMA guidances (11) and has been supported by FDA scientists (12) and has recently been incorporated into a guidance (10). Class 2 drugs may experience clinically relevant changes from both metabolizing enzymes and efflux transporters in the gut, liver, and brain and uptake transporters in the liver and brain. Class 3 and 4 drugs are unlikely to be affected by changes in metabolism, but may be affected by uptake or efflux transporters in the gut, liver, or brain. Clinically relevant transporter effects in the kidney have yet to be ascertained, though we have discussed the likely effects (13).

Recent work in our laboratory and others has progressed toward expanding the applications of BDDCS and applying the predictions to new molecular entities. The utilities of BDDCS are enumerated in various publications $(5,13,14)$. BDDCS can be used in both discovery and development. Predictions include drug-drug interactions (DDIs), pharmacogenomic effects, food effects, endogenous substrate effects, distribution, and elimination route. As our understanding of drug transporters and metabolizing enzymes progresses, so do the applications of this system. BDDCS may predict toxicity, transporter-mediated drug resistance, and environmental impacts, and may inform drug delivery and dosage. Indeed, BDDCS could be a powerful predictive tool any time a drug transporter is involved in a physiological process.

\section{TRANSPORTER AND METABOLIZING ENZYME EXPRESSION AND ACTIVITY}

\section{Predicting Drug-Drug Interactions}

Of all Americans, $21.7 \%$, and of Americans older than 65 years, more than $65 \%$, take three or more prescription drugs (15). When taking two or more drugs, the safety or efficacy of one or more drugs may potentially be compromised by one of the other drugs (DDIs). BDDCS can predict when the inhibition or induction of metabolizing enzymes or uptake or efflux transporters in the gut or liver may alter a drug's pharmacokinetic profile and therefore efficacy and safety. Concomitantly administered drugs and endogenous compounds may induce and/or inhibit transporters and/or enzymes, while genomic differences can alter the expression or activity of transporters or enzymes.

As BDDCS class 1 drugs are unaffected in a clinically relevant manner by the inhibition or induction of drug transporters, one obvious and major advance of BDDCS is waiving substrate transporter studies for an extensively metabolized, highly soluble compound. BDDCS class 1 drugs do not need to be evaluated as substrates of transporters, and if they are substrates in vitro, clinical studies do not need to be conducted. As BDDCS class 1 drugs comprise $40 \%$ of marketed drugs and $18 \%$ of new molecular entities (13), waiving transporter substrate studies would substantially reduce the developmental burden. However, while BDDCS class 1 drugs are unlikely to be victims of a transportermediated DDI, their status as inhibitors or inducers of transporters should be assessed, as they may still perpetrate transporter inhibition or induction and may clinically affect a non-class 1 drug.

BDDCS class should inform substrate selection in DDI studies. The FDA interaction guidance recommends metabolizing enzyme and transporter substrates to test if an NME is an inhibitor or an inducer of an enzyme or transporter (2). While the enzyme substrates are all extensively metabolized BDDCS class 1 and 2 substrates and are therefore appropriate for in vitro and in vivo interaction studies, some of the substrates listed for transporter interaction studies are class 1 compounds. Use of class 1 compounds as substrates in vivo may incorrectly suggest that the transporter in question is not inhibited or induced, which in fact may be apparent when using a class 2,3 , or 4 substrate (victim) drug.

\section{Impact of Pharmacogenomics, Endogenous Substrates, and Food Effects}

BDDCS can predict when pharmacogenetic variants or endogenous compounds may have an impact on a drug's pharmacokinetics (Box 1). For instance, a poorly permeable BDDCS class 3 or 4 drug will not be clinically impacted by genetic variants of CYP2C19, while a high permeability rate drug will need to be evaluated for CYP2C19 metabolism, as about $20 \%$ of Asians lack expression of CYP2C19 and do not 
metabolize its substrates (16), while pharmacogenomic differences in transporters are unlikely to impact the safety and efficacy of a class 1 drug. Concentrations of endogenous compounds can be increased or decreased by disease and can act as inhibitors or inducers of transporters and metabolizing enzymes. Importantly, the FDA recommends that investigational drugs be evaluated for pharmacokinetic changes in patients with impaired renal function or end-stage renal disease as transporter and/or enzyme inhibition from high concentrations of uremic toxins may alter pharmacokinetics, even if the compound is not renally eliminated (17). Additionally, diet can impact a drug's pharmacokinetics. BDDCS can correctly predict effects of high-fat meals on bioavailability for about $70 \%$ of drugs (18).

\section{Toxicity Predictions}

Additionally, BDDCS may predict when certain druginduced toxicities, such as Torsade de Pointes (TdP) (19), drug-induced liver injury (DILI) (20), and anti-epileptic drug cutaneous hypersensitivity (21), may be a clinical concern. BDDCS has linked a major role of intestinal metabolism and intestinal transporters in drug-induced toxicity. For example, BDDCS helped schematize for which drugs hERG (human Ether-à-go-go Related Gene) voltage-gated potassium channel inhibition is likely to result in $\operatorname{TdP}(22,23)$ from drug-drug interactions due to CYP or P-gp inhibition (24). For BDDCS class 2 hERG inhibitors that are also substrates of both CYP and P-gp, the dual inhibition of metabolism and transport could significantly increase the plasma concentration leading to more cases of severe toxicity. For BDDCS class $1 \mathrm{hERG}$ inhibitors, the effect of P-gp should be less pronounced and result in a more moderate toxicity. BDDCS class 3 and class 4 drugs are less likely to be hERG inhibitors and therefore less likely to cause TdP. BDDCS may help characterize drugs with severe toxicity potential by better understanding their extent of metabolism and transporter interplay with other physicochemical properties and/or biomarkers that can be associated with toxicity.

\section{Drug Resistance}

Conditions provoked by rapidly evolving cells, e.g., cancer cells or bacteria, can be subject to drug resistance. This resistance is often mediated by the increased expression or activity of drug efflux transporters on the target cell. BDDCS class 1 drugs, which are not clinically affected by transporters, may therefore be protected from drug resistance.

\section{PREDICTING DISTRIBUTION AND ELIMINATION}

\section{Central Nervous System Effects}

During discovery and development, BDDCS can predict when central effects may or may not occur. P-gp has the potential to modify brain concentrations. It was hypothesized that for a drug to successfully penetrate and reside in the brain to achieve a pharmacodynamic effect, a drug should not be a P-gp substrate, while to avoid a central effect, e.g., drowsiness with antihistamines, a drug can be designed as a P- gp substrate. However, we have recently demonstrated that highly permeable/extensively metabolized, highly soluble (BDDCS class 1) compounds can have a central pharmacodynamic effect at clinically approved doses, even if the drug is a substrate for P-gp, regardless of whether the effect is desired (25). Therefore, it is preferable for a peripherally acting drug to be either poorly permeable and a non-substrate for uptake transporters in the brain, or poorly soluble and a $\mathrm{P}$-gp substrate-or both-while efflux is not a concern in the efficacy of highly permeable/highly soluble drugs intended for central effects.

\section{Predicting Elimination Routes}

As BDDCS recognizes that compounds with a high intestinal permeability rate will be extensively metabolized, we can usefully predict which of the three major routes of elimination: metabolism, renal excretion of unchanged drug, or biliary excretion of unchanged drug, will predominate in a drug's elimination. We have shown that the primary elimination route can be well predicted using in vitro permeability rates to predict the extent of metabolism, segregating classes 1 and 2 from 3 and 4, while two computed molecular features of a drug, metabolic stability and polarizability, can then predict if a poorly metabolized drug is eliminated in the bile or the urine as unchanged drug $(26,27)$. These predictions may be very valuable during drug discovery and development. The major route of elimination can significantly impact if a drug can be safely and effectively administered to patients. For instance, renal elimination of unchanged drug should be avoided in patients with kidney failure. As such, drugs intended for treatment of a disease with significant comorbidity with renal failure, e.g., diabetes, should be designed with the expectation that they are eliminated by metabolism or in the bile. Alternatively, discovery scientists could adopt prediction of the major elimination route as a means of delivery to a target organ, such as the liver.

\section{ADDITIONAL CONSIDERATIONS: ENVIRONMENTAL IMPLICATIONS AND DOSE DIFFERENCES}

Recently, Daughton (28) suggested that BDDCS could be used in an attempt to decrease environmental exposure of active pharmaceutical ingredients. In particular, BDDCS class 1 drugs are likely to leave smaller environmental levels due to good absorption and significant biotransformation, while hypothesizing that class 4 drugs require higher doses as a result of poor permeability and poor solubility and thus generally poor absorption and are primarily excreted unchanged, resulting in higher environmental levels. We therefore analyzed dosages between the four classes and noted significant differences in doses between the classes, such that class 4 compounds were dosed significantly higher than all the other classes when a compound was given orally and higher than classes 1 and 2 when a compound was administered intravenously (Fig. 1). A possible explanation for higher required doses would be a higher clearance for class 4 compounds, but we actually saw the opposite trend-that class 1 compounds had higher clearance than the other classes-and therefore, this is not a plausible explanation 

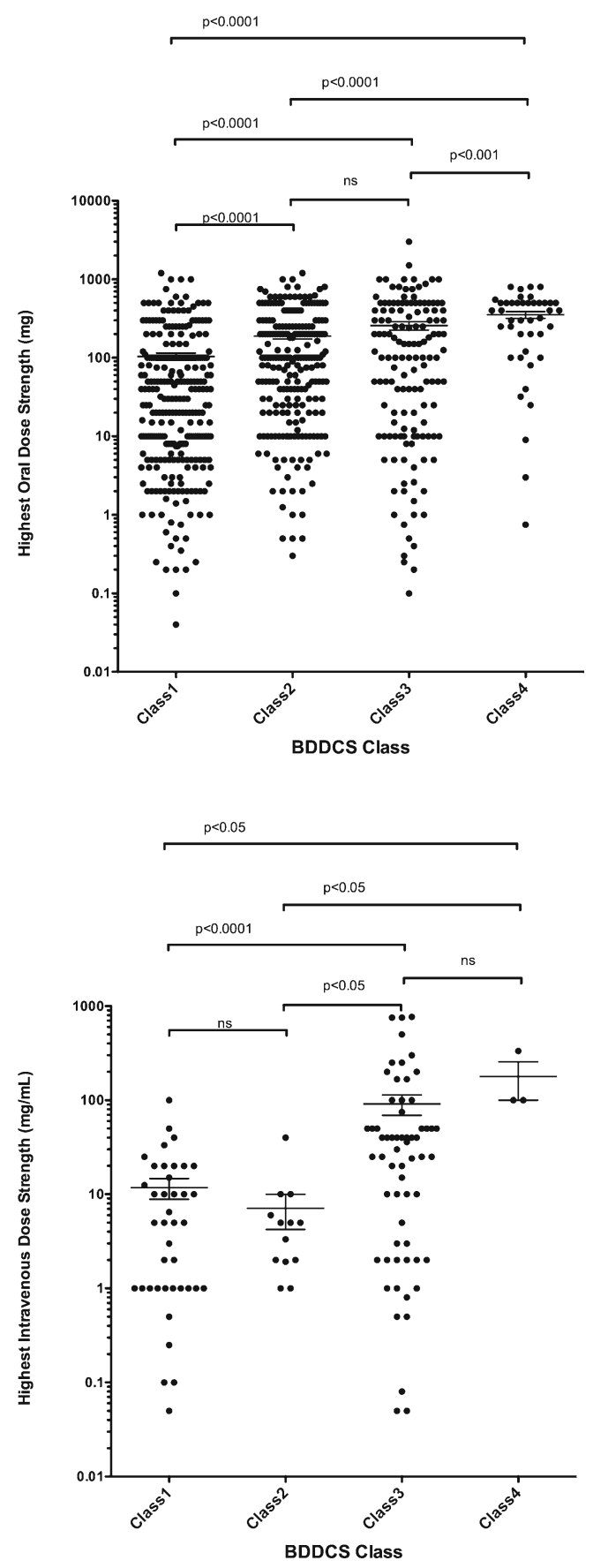

Fig. 1. Dose differences between BDDCS classes

(data not shown). We also note that class 3 compounds are significantly overrepresented in the intravenously administered compounds, likely a result of necessity of intravenous dosing due to poor permeability rate and ease of dissolution due to high solubility.

\section{PREDICTING BDDCS CLASS}

Preclinically, BDDCS class can be predicted in vitro. In vitro permeability rate measurements in Caco-2, MDCK, or PAMPA can reliably predict the extent of metabolism of drugs, while FDA solubility is measured in vitro by definition. Varma et al. (29) correctly predicted the BDDCS class for 41/
49 (84\%) drugs using permeability rate measured in MDCKLE cells and $\mathrm{pH}$-dependent in vitro solubility, measured at $\mathrm{pH}=1.2$ in simulated gastric fluid and at $\mathrm{pH}=6.5$ in $50 \mathrm{mM}$ PBS or FaSSIF (29). To expand predictability between labs, we recently prioritized high permeability rate drugs to be used as standards in predicting the extent of metabolism: labetalol in Caco-2, zidovudine in MDCK, and theophylline in PAMPA (26). In silico, Broccatelli et al. (24) correctly predicted the BDDCS class for $55 \%$ of molecules, though $92 \%$ of the molecules were predicted by one of the top two ranked classes. Benet et al. (30) showed that in silico predictions of the minimum solubility of drugs over the $\mathrm{pH}$ range 3-7.5 are well segregated between class 2 and 3 drugs, but are unexpectedly similar when comparing class 1 and 4 drugs. Similarly, CLogP, serving as a permeability rate surrogate, is able to differentiate between classes 2 and 3, but confounds classes 1 and 4 . These relatively simple in silico parameters are therefore able to predict when a drug is likely to be class 2 or 3 , but a drug having a more moderate $\log \mathrm{P}$ $(0<\log \mathrm{P}<2)$ or predicted minimum solubility is unable to be accurately classified. Additionally, we have shown that there is no significant difference in the measured or calculated $\log \mathrm{P}$ of extensively metabolized class 1 and 2 compounds and class 3 and 4 compounds primarily eliminated as unchanged drug in the bile, although both are significantly higher than the $\operatorname{LogP}$ of renally eliminated compounds (26). Therefore, $\log P$ is an unreliable indicator of BDDCS class. While we continue to investigate these confounding factors, currently, the best prediction approach remains in vitro.

\section{THE SELF-CORRECTING ASPECTS OF BDDCS ASSIGNMENTS}

Benet et al. compiled a list of over 900 drugs containing the BDDCS class, properties of the drug including administration route and fraction of the drug excreted unchanged in the urine, and various physicochemical parameters such as solubility, partition coefficient $(\log P)$, and molecular weight (30). One advantage to understanding this system is that BDDCS class indicates if a drug is extensively $(\geq 70 \%)$ or poorly $(\leq 30 \%)$ metabolized, which, when combined with the fraction of the drug excreted unchanged in the urine, was used to create a dataset of compounds eliminated primarily as unchanged drug in the bile. We therefore were able to classify drugs into their primary elimination route: extensive metabolism, renal elimination as parent drug, or biliary elimination as parent drug. As a result, we were able to develop a system of predicting the major elimination route using in vitro permeability rate measurements to predict the extent of metabolism followed by a two-feature logistic regression model including calculated metabolic stability and polarizability that predicts when a poorly permeable, orally administered drug is likely to be eliminated primarily as unchanged drug in the bile or primarily as unchanged drug in the urine (27).

Here, we show that BDDCS has a feedback quality whereby its properties make mistakes obvious to allow reflection of reported properties (i.e., metabolism and solubility) and correct itself. This may not be immediately apparent upon classification, but as drug studies progress, outliers become glaring and demand revisiting. BDDCS 
errors generally stem from poorly reported data. Given that BCS or BDDCS classification is becoming relatively common in the pharmaceutical industry, new molecular entities may be less susceptible to mistakes, since most drugs were initially classified from a variety of literature sources whose measurements were not developed to predict BCS or BDDCS class. Updated and selective methodology and experiments conducted at single sites may provide more accurate measurements and predictions. We have only seen a few exceptions where the drug does not match the predicted dispositional rules and where we believe that the measurements are accurate, namely the statins fluvastatin and cerivastatin.

\section{Corrections Recognized by Discrepancies Between Permeability Rate and Extent of Metabolism}

When we considered in vitro permeability rate as a predictor of the extent of metabolism, we discovered that flecainide (31), clonidine (32,33), metoclopramide (29), phenazopyridine (29), and pindolol (32), while listed as BDDCS class 3 and 4 compounds, were highly permeable in vitro. Thus, upon further investigation, it was noted that these compounds are extensively metabolized (34-38). Literature indicated that colchicine is a low permeability rate drug, while we initially classified colchicine as BDDCS class 1 . We realized that this compound was eliminated in the bile (Table I). Importantly, colchicine was also identified as the sole false negative of highly permeable BDDCS class 1 compounds that were P-gp substrates when predicting CNS exposure (24). Aliskiren and cefoperazone are poorly permeable and eliminated in the bile $(39,40)$, although we initially classified them as extensively metabolized/highly permeable. We utilized aliskiren as an external validation compound in our model predicting when biliary elimination is the major route of elimination and adjusted its class to class 3 for further studies. Diclofenac was listed with a high solubility, but a much lower solubility has been reported (41) (Table II), resulting in a dose number of 1.4, and therefore necessitated a classification change to class 2 . Changes to BDDCS class are listed in Table I. Changes to BDDCS class or listed properties are listed in Table II.

\section{Discrepancies in Predicted and Actual Elimination Route}

During development of our model predicting the major route of elimination of orally administered BDDCS class 3 and 4 drugs, we believed ranitidine was misclassified, having a listed fraction excreted unchanged in the urine as $30 \%$, but was predicted as primarily eliminated in the urine. We discovered that the fraction of the bioavailable dose excreted in the urine was actually $69 \%$ and was therefore correctly predicted (42). In this publication, we considered efflux transporters of biliarily eliminated drugs. Saxagliptin was incorrectly predicted by the model and was not noted to be a substrate of any efflux transporters, as expected. After inspecting its approval package, we realized that saxagliptin is extensively metabolized (43) and amended its class to class 1. In this same investigation, vancomycin was predicted to be eliminated in the bile, despite being primarily eliminated in the urine. Here, we realized that vancomycin was listed as orally dosed, despite primarily being administered
Table I. BDDCS Class Changes from Initial Publication

\begin{tabular}{llll}
\hline Compound & $\begin{array}{l}\text { Listed } \\
\text { class }^{\mathrm{a}}\end{array}$ & $\begin{array}{l}\text { Updated } \\
\text { class }\end{array}$ & $\begin{array}{l}\text { Major route of } \\
\text { elimination }\end{array}$ \\
\hline Aliskiren & 1 & 3 & Biliary \\
Cefoperazone & 1 & 3 & Biliary \\
Clonidine & 3 & 1 & Metabolism \\
Colchicine & 1 & 3 & Biliary \\
Dabigatran & 3 & 4 & Renal \\
Diclofenac & 1 & 2 & Metabolism \\
Flecainide & 3 & 1 & Metabolism \\
Metoclopramide & 3 & 1 & Metabolism \\
Phenazopyridine & 4 & 2 & Metabolism \\
Pindolol & 3 & 1 & Metabolism \\
Pitavastatin & 2 & 4 & Biliary \\
Saxagliptin & 3 & 1 & Metabolism \\
Tiagabine $\mathrm{HCl}$ & 2 & 1 & Metabolism \\
\hline
\end{tabular}

${ }^{a}$ As listed in Benet et al. (30)

intravenously and is unabsorbed and intended for pseudomembranous colitis when administered orally. A similar anomaly was observed with tiotropium bromide, which is an inhaled drug (44). We recognized that successful segregation of renally and biliarily eliminated drugs was limited to orally administered drugs by this model, where some non-orally administered drugs that are renally eliminated could be confounded with [orally or non-orally administered] biliarily eliminated drugs. Enalaprilat was correctly identified, but was initially listed as an orally administered compound, but is in fact given intravenously. Characteristic changes of drugs unrelated to BDDCS class are listed in Table II.

\section{Additions to BDDCS}

While building this model, we also considered the fate of recently approved drugs. Three compounds were labeled with significant biliary elimination (afatinib, teriflunomide, vismodegib). These compounds will therefore be classified as BDDCS class 3 or 4 . The following compounds were published in a dataset (45) compiling when biliary excretion was significant and have been assigned class 3 or 4:

Table II. Parameter Changes from Initial Publication

\begin{tabular}{lll}
\hline Compound & $\begin{array}{l}\text { Parameter value } \\
\text { listed }\end{array}$ & $\begin{array}{l}\text { Updated parameter } \\
\text { value }\end{array}$ \\
\hline Memantine & \% dose excreted as & $\begin{array}{c}\text { unchanged drug in urine } \\
\text { Pravastatin }\end{array}$ \\
Ranitidine & 20 & 48 \\
Rosuvastatin & 30 & 47 \\
& 5 & 69 \\
Atorvastatin & Solubility & 30 \\
Diclofenac & $9.0000204 \mathrm{mg} / \mathrm{mL}$ & $0.0204 \mathrm{mg} / \mathrm{mL}$ \\
& Administration route & \\
Enalaprilat & Oral & Intravenous \\
Vancomycin & Oral & Intravenous \\
Tiotropium & Oral & Inhaled \\
bromide & & \\
\hline
\end{tabular}


cefbuperazone, cephaloridine, emepronium, flomoxef, indocyanine green, and temafloxacin. More than 175 additions to BDDCS classification, including these listed above and other compounds recently classified $(46,47)$, are listed in Table III.

In Table III, we added boceprevir, a drug used to treat hepatitis C. The highest dose strength of boceprevir is a 200mg capsule, although four of these capsules are indicated per administration. Therefore, although the summary basis of approval classifies this drug as a low solubility class 4 drug based on a dose of $800 \mathrm{mg}$, we have classified this drug as a BDDCS class 1 drug based on the highest dose strength of $200 \mathrm{mg}$. In cases like boceprevir, classifications can sometimes be misleading, but classification consistency is necessary. BDDCS uses the FDA definition of solubility, as indicated in bioequivalence guidelines (10). However, the solubility criteria differ between regulatory agencies. The EMA has recently recommended that the highest dose given in a single setting according to a drug's labeling be used to calculate the dose number for biowaivers $(48,49)$. In general, this is some multiple of the highest dose strength. For instance, if $80 \mathrm{mg}$ was dosed in a single setting, but as two 40-mg tablets, where tablets greater than $40 \mathrm{mg}$ were not developed, the FDA would allow biowaivers on the basis of the 40-mg dose, while the EMA would require dose number calculation based on an 80-mg dose. This can impact a few high-solubility compounds, shifting their classification to a low-solubility class and different dispositional properties would be predicted, particularly if the compound is highly permeable and extensively metabolized. The approach recommended by the EMA is a more conservative approach and fewer drugs are qualified for a biowaiver. This approach would also limit the percentage of class 1 drugs, imposing slightly stricter standards to predict when transport is clinically irrelevant. However, this results in a change for only a small percentage of drugs. Solubility is a relatively inherent property of the drug, and relatively few drugs have such a significant change in dose that will result in a change of solubility classification. Recently, Sediq et al. (48) examined 27 drugs for which a biowaiver monograph was published for changes in classification mediated by differences in dose definition. Of the 27 , only $4(15 \%)$ of the drugs required a classification change.

\section{CAUTIONS}

In their 2005 paper (5), Wu and Benet included a section under the heading "Cautions," where they stated, "There will always be exceptions to the broad general rules presented here." One of the most useful predictions from BDDCS, as noted earlier, is that the clinical relevance of transporters for BDDCS class 1 drugs is negligible. However, as very recently reported by Varma et al. (50), the rate-limiting step for elimination of all statins appears to be hepatic uptake by OATPs independent of BDDCS class, including the class 1 statins cerivastatin and fluvastatin. While our outliers have been explained by incorrectly reported or interpreted data leading to misclassification, any predictive system will have some unexplained outliers. Our laboratory is currently investigating possible mechanisms for the unexpected transporter interactions of these class 1 statins. We expect that there may be further violations of our statement that BDDCS class 1 drugs are unaffected in a clinically relevant manner by
Table III. Newly BDDCS Classified Drugs

\begin{tabular}{|c|c|}
\hline Drug & Class \\
\hline Afatinib & 3 \\
\hline Alclofenac & 2 \\
\hline Alpidem & 1 \\
\hline Amifloxacin & 3 \\
\hline Amineptine & 1 \\
\hline Aminosalicylic acid & 1 \\
\hline Axitinib & 2 \\
\hline Azimilide & 1 \\
\hline Bendazac & 2 \\
\hline Benoxaprofen & 2 \\
\hline Benzarone & 2 \\
\hline Benzbromarone & 2 \\
\hline Benziodarone & 2 \\
\hline Benzonatate & 2 \\
\hline Benzphetamine & 0 \\
\hline Benztropine & 1 \\
\hline Betaine & 1 \\
\hline Bethanechol & 3 \\
\hline Bidisomide & 3 \\
\hline Boceprevir & 1 \\
\hline Brexpiprazole & 2 \\
\hline Bromfenac & 2 \\
\hline Brotizolam & 1 \\
\hline Canagliflozin & 2 \\
\hline Carbinoxamine & 1 \\
\hline Carbovir & 4 \\
\hline Carisoprodol & 1 \\
\hline Cefbuperazone & 3 \\
\hline Cefcanel & 3 \\
\hline Cefmenoxime & 3 \\
\hline Cefoperazone & 3 \\
\hline Cefpirome & 3 \\
\hline Ceftolazone & 3 \\
\hline Cephaloridine & 3 \\
\hline Chlorhexidine & 3 \\
\hline Chlormezanone & 1 \\
\hline Chlorpropamide & 0 \\
\hline Cinchophen & 2 \\
\hline Ciprofibrate & 2 \\
\hline Clinafloxacin & 3 \\
\hline Clomacran & 2 \\
\hline Clometacin & 2 \\
\hline Clopamide & 3 \\
\hline Cobicistat & 2 \\
\hline Cotinine & 1 \\
\hline Crizotinib & 2 \\
\hline Cyclofenil & 2 \\
\hline Dabrafenib & 2 \\
\hline Daclatasvir & 4 \\
\hline Dapagliflozin & 1 \\
\hline Dasabuvir & 2 \\
\hline Deferasirox & 2 \\
\hline Dexfenfluramine & 1 \\
\hline Dexloxiglumide & 1 \\
\hline Dihydralazine & 1 \\
\hline Dihydroergotamine & 1 \\
\hline Dolutegravir & 2 \\
\hline Dopamine & 1 \\
\hline Droxicam & 2 \\
\hline Ebrotidine & 1 \\
\hline Edoxaban & 4 \\
\hline Eltrombopag & 2 \\
\hline Emepronium & 3 \\
\hline
\end{tabular}


Table III. (continued)

\begin{tabular}{|c|c|}
\hline Drug & Class \\
\hline Empagliflozin & 1 \\
\hline Encainide & 1 \\
\hline Enprofylline & 3 \\
\hline Fenclozic Acid & 2 \\
\hline Fenoterol & 1 \\
\hline Fenoprofen & 2 \\
\hline Fialuridine & 2 \\
\hline Finafloxacin & 4 \\
\hline Fipexide & 3 \\
\hline Flavoxate & 2 \\
\hline Flibanserin & 2 \\
\hline Flomoxef & 3 \\
\hline Flucloxacillin & 4 \\
\hline Flupirtine & 1 \\
\hline Fosaprepitant & 1 \\
\hline Fosfluconazole & 1 \\
\hline Fosinapril & 1 \\
\hline Fosinaprilat & 3 \\
\hline Fusidic acid & 2 \\
\hline Genistein & 1 \\
\hline Glafenine & 2 \\
\hline Guanethidine & 1 \\
\hline Ibufenac & 2 \\
\hline Indocyanine green & 3 \\
\hline Iproniazid & 1 \\
\hline Isocarboxazid & 1 \\
\hline Isoproterenol & 1 \\
\hline Isoxepac & 2 \\
\hline Ivacaftor & 2 \\
\hline Ketotifen & 1 \\
\hline Ledipasvir & 4 \\
\hline Lesinurad & 2 \\
\hline Levovirin & 3 \\
\hline Licarbazepine & 1 \\
\hline Liothyronine & 2 \\
\hline Lofexadine & 1 \\
\hline Lumiracoxib & 2 \\
\hline Meclizine & 1 \\
\hline Meclofenamic acid & 2 \\
\hline Mepazine & 1 \\
\hline Mephenytoin & 2 \\
\hline Metaproterenol & 1 \\
\hline Methapyrilene & 1 \\
\hline Methimazole & 1 \\
\hline Methoxsalen & 2 \\
\hline Methysergide & 1 \\
\hline Metolazone & 3 \\
\hline Metyrapone & 1 \\
\hline Metyrosine & 4 \\
\hline Mibefradil & 2 \\
\hline Mifepristone & 2 \\
\hline Nedocromil & 3 \\
\hline Nemonapride & 2 \\
\hline Nialamide & 1 \\
\hline Nisoldipine & 2 \\
\hline Nomifensine & 1 \\
\hline Olaparib & 2 \\
\hline Ombitasvir & 4 \\
\hline Oxandrolone & 2 \\
\hline Oxymetholone & 1 \\
\hline Oxyphenisatine & 2 \\
\hline Oxytetracycline & 3 \\
\hline Pargyline & 1 \\
\hline
\end{tabular}

Table III. (continued)

\begin{tabular}{|c|c|}
\hline Drug & Class \\
\hline Paritapravir & 2 \\
\hline Paromomycin & 3 \\
\hline Pasireotide & 3 \\
\hline Pazopanib & 2 \\
\hline Pelrinone & 3 \\
\hline Pemoline & 3 \\
\hline Penbutolol & 2 \\
\hline Peramivir & 3 \\
\hline Perampanel & 2 \\
\hline Phencyclidine & 1 \\
\hline Phendimetrazine & 0 \\
\hline Phenformin & 3 \\
\hline Phenoxybenzamine & 1 \\
\hline Phentermine & 3 \\
\hline Phentolamine & 1 \\
\hline Physostigmine & 1 \\
\hline Pinacidil & 2 \\
\hline Pirprofen & 2 \\
\hline Practolol & 3 \\
\hline Pralidoxime & 3 \\
\hline Procyclidine & 1 \\
\hline Rebamipide & 4 \\
\hline Roquinimex & 2 \\
\hline Rilpivirine & 2 \\
\hline Sabeluzole & 2 \\
\hline Sapropterin dihydrochloride & 1 \\
\hline Sertindole & 2 \\
\hline Simeprevir & 2 \\
\hline Sinitrodil & 1 \\
\hline Sofosbuvir & 3 \\
\hline Tasosartan & 2 \\
\hline Telapavir & 2 \\
\hline Temafloxacin & 3 \\
\hline Temocaprilat & 3 \\
\hline Teriflunomide & 4 \\
\hline Tedizolid phosphate & 1 \\
\hline Tesaglitazar & 2 \\
\hline Thiotepa & 1 \\
\hline Tiapride & 3 \\
\hline Ticagrelor & 2 \\
\hline Ticrynafen & 2 \\
\hline Tolrestat & 3 \\
\hline Tranexamic acid & 3 \\
\hline Troglitazone & 2 \\
\hline Trovafloxacin acid & 3 \\
\hline Trovafloxacin mesylate & 1 \\
\hline Vandetanib & 2 \\
\hline Vemurafenib & 2 \\
\hline Vismodegib & 4 \\
\hline Vorinostat & 2 \\
\hline Xamoterol & 3 \\
\hline Yohimbine & 1 \\
\hline Zomepirac & 2 \\
\hline Zotepine & 2 \\
\hline
\end{tabular}

the inhibition or induction of drug transporters, but we are unaware at this time of documented examples. Additional data may indicate the need to amend and/or grow BDDCS and generate new hypotheses. Here, we have amended our prediction that class 1 drugs will not be clinically affected by hepatic uptake transporters to exclude statins (Box 1). 
Most recently, we have begun to consider the possibility of using BDDCS as a tool in evaluating toxicity potential (21). Therefore, the expanded list of BDDCS drug classification here (Table III) includes many drugs that have been removed from the market as a result of toxic manifestations. Expansion of the BDDCS classification list was particularly challenging since for many drugs that came onto the market a number of years ago, and then removed because of toxicity, little reliable information both in terms of metabolism and solubility can be found in the literature. Therefore, when a drug is on the border of two classes, the BDDCS class is selected based on expected or known drug interactions. Finally, one of the reasons for drugs' misclassification in BDDCS classes can be the simplified, binary, non-continuous structure of BCS and BDDCS. This is particularly so for drugs lying on the border of two classes. While BCS and BDDCS are classification systems based on binary decisions, each property is measured on a continuous scale. It is therefore expected that compounds that approach the binary boundaries may be more difficult to evaluate and inherently risk potential misclassification.

\section{CONCLUSION}

As we have developed models that confirm and inform BDDCS predictions or utilized BDDCS predictions to guide methods and hypothesis development, we have naturally encountered drugs with surprising outcomes. In these cases, we can often explain outliers with a model specific limitation or a physiological mechanism that overcomes the base prediction. For instance, Broccatelli et al. predicted that highly permeable P-gp substrates that were not class 1 would not be exposed to the central nervous system (25). Yet, in many cases, an uptake transporter overwhelmed the effect of P-gp. However, when mechanistic explanations cannot be determined, we often found that a misclassification was present in the initial dataset, and when we reviewed the solubility or extent of metabolism, we realized that a correction to the BDDCS classification was warranted.

BDDCS can self-correct when discrepancies are seen between predicted and observed effects, as we have seen with drugs such as aliskiren, colchicine, and others. Results of a BDDCS-based experiment often inform the analyst of the true BDDCS class, and if other factors cannot explain a discrepancy, the analyst should consider reviewing the extent of metabolism and solubility of the drug to determine if reclassification is necessary.

\section{ACKNOWLEDGMENTS}

CMH was supported in part by NIH Training Grant T32 GM007175 and the Pharmaceutical Research and Manufacturers of America (PhRMA) Foundation Pre Doctoral Fellowship in Pharmaceutics. RC was supported in part by the American Foundation for Pharmaceutical Education.

\section{REFERENCES}

1. Wacher VJ, Salphati L, Benet LZ. Active secretion and enterocytic drug metabolism barriers to drug absorption. Adv Drug Deliv Rev. 1996;20(1):99-112.
2. Food and Drug Administration Center for Drug Evaluation and Research. Guidance for industry: drug interaction studies- study design, data analysis, implications for dosing, and labeling recommendations. US FDA website: http://www.fda.gov/downloads/Drugs/GuidanceComplianceRegulatoryInformation/Guidances/UCM292362pdf. 2012 Feb 16;:1-79.

3. Giacomini KM, Huang S-M, Tweedie DJ, Benet LZ, Brouwer KLR, Chu X, et al. Membrane transporters in drug development. Nat Rev Drug Discov. 2010;9(3):215-36.

4. Rinaki E, Valsami G, Macheras P. Quantitative biopharmaceutics classification system: the central role of dose/solubility ratio. Pharm Res. 2003;20(12):1917-25.

5. Wu C-Y, Benet LZ. Predicting drug disposition via application of BCS: transport/absorption/ elimination interplay and development of a biopharmaceutics drug disposition classification system. Pharm Res. 2005;22(1):11-23.

6. Amidon GL, Lennernäs H, Shah VP, Crison JR. A theoretical basis for a biopharmaceutic drug classification: the correlation of in vitro drug product dissolution and in vivo bioavailability. Pharm Res. 1995;12(3):413-20.

7. Gustafson JH, Benet LZ. Biliary excretion kinetics of phenolphthalein glucuronide after intravenous and retrograde biliary administration. J Pharm Pharmacol. 1974;26(12):937-44.

8. Dave RA, Morris ME. Quantitative structure-pharmacokinetic relationships for the prediction of renal clearance in humans. Drug Metab Dispos. 2015;43(1):73-81.

9. Varma MVS, Feng B, Obach RS, Troutman MD, Chupka J, Miller HR, et al. Physicochemical determinants of human renal clearance. J Med Chem. 2009;52(15):4844-52.

10. Food and Drug Administration Center for Drug Evaluation and Research. Guidance for industry: waiver of in vivo bioavailability and bioequivalence studies for immediate-release solid oral dosage forms based on a biopharmaceutics classification system. US FDA website: http://www.fda.gov/downloads/Drugs/Guidances/ucm070246.pdf. 2015. pp. 1-14.

11. Committee for Medicinal Products for Human Use, European Medicines Agency. Guideline on the investigation of bioequivalence [Internet]. 2010 Jan. Available from: http:// www.ema.europa.eu/docs/en_GB/ document_library/ Scientific_guideline/2010/01/WC500070039.pdf

12. Chen M-L, Amidon GL, Benet LZ, Lennernäs H, Yu LX, BCS. BDDCS, and regulatory guidances. Pharm Res. 2011;28(7):1774-8.

13. Benet LZ. The role of BCS (Biopharmaceutics Classification System) and BDDCS (Biopharmaceutics Drug Disposition Classification System) in drug development. J Pharm Sci. 2013;102(1):34-42.

14. Shugarts S, Benet LZ. The role of transporters in the pharmacokinetics of orally administered drugs. Pharm Res. 2009;26(9):2039-54.

15. National Center for Health Statistics. Health, United States, 2012 with Special Features on Emergency Care. 2013 Apr 1;:1-505.

16. Desta Z, Zhao X, Shin J-G, Flockhart DA. Clinical significance of the cytochrome P450 2C19 genetic polymorphism. Clin Pharmacokinet. 2002;41(12):913-58.

17. Food and Drug Administration Center for Drug Evaluation and Research. Guidance for industry: pharmacokinetics in patients with impaired renal function - study design, data analysis, and impact on dosing and labeling. US FDA website: http:// w w w. f d a . g o v/d o w n l o a d s / D r u g s / GuidanceComplianceRegulatoryInformation/Guidances/ UCM292362.pdf. 2010. pp. 1-21.

18. Custodio JM, Wu C-Y, Benet LZ. Predicting drug disposition, absorption/elimination/transporter interplay and the role of food on drug absorption. Adv Drug Deliv Rev. 2008;60(6):717-33.

19. Broccatelli F, Mannhold R, Moriconi A, Giuli S, Carosati E. QSAR modeling and data mining link Torsades de Pointes risk to the interplay of extent of metabolism, active transport, and HERG liability. Mol Pharm. 2012;9(8):2290-301.

20. Vuppalanchi R, Gotur R, Reddy KR, Fontana RJ, Ghabril M, Kosinski AS, et al. Relationship between characteristics of medications and drug-induced liver disease phenotype and outcome. Clin Gastroenterol Hepatol. 2014;12(9):1550-5.

21. Chan R, Benet LZ. Predicting which anti-epileptic drugs will cause HLA-associated drug hypersensitivity using BDDCS 
[Internet]. 2014 AAPS Annual Meeting and Exposition. San Diego, CA; 2014. pp. 1-1. Available from: http:// abstracts.aaps.org/Verify/AAPS2014/PosterSubmissions/ T3375.pdf

22. Sanguinetti MC, Jiang C, Curran ME, Keating MT. A mechanistic link between an inherited and an acquired cardiac arrhythmia: HERG encodes the IKr potassium channel. Cell. 1995;81(2):299-307.

23. Trudeau MC, Warmke JW, Ganetzky B, Robertson GA. HERG, a human inward rectifier in the voltage-gated potassium channel family. Science. 1995;269(5220):92-5.

24. Broccatelli F, Cruciani G, Benet LZ, Oprea TI. BDDCS class prediction for new molecular entities. Mol Pharm. 2012;9(3):57080.

25. Broccatelli F, Larregieu CA, Cruciani G, Oprea TI, Benet LZ. Improving the prediction of the brain disposition for orally administered drugs using BDDCS. Adv Drug Deliv Rev. 2012;64(1):95-109.

26. Hosey CM, Benet LZ. Predicting the extent of metabolism using in vitro permeability rate measurements and in silico permeability rate predictions. Mol Pharm. 2015;12(5):1456-66.

27. Hosey CM, Broccatelli F, Benet LZ. Predicting when biliary excretion of parent drug is a major route of elimination in humans. AAPS J. 2014;16(5):1085-96.

28. Daughton CG. Eco-directed sustainable prescribing: feasibility for reducing water contamination by drugs. Sci Total Environ. 2014;493:392-404.

29. Varma MV, Gardner I, Steyn SJ, Nkansah P, Rotter CJ, WhitneyPickett $\mathrm{C}$, et al. $\mathrm{pH}$-dependent solubility and permeability criteria for provisional biopharmaceutics classification (BCS and BDDCS) in early drug discovery. Mol Pharm. 2012;9(5):1199212.

30. Benet LZ, Broccatelli F, Oprea TI. BDDCS applied to over 900 drugs. AAPS J. 2011;13(4):519-47.

31. Sugano K, Takata N, Machida M, Saitoh K, Terada K. Prediction of passive intestinal absorption using bio-mimetic artificial membrane permeation assay and the paracellular pathway model. Int J Pharm (Amsterdam, Neth). 2002;24(2):241-51.

32. Zhu C, Jiang L, Chen T-M, Hwang K-K. A comparative study of artificial membrane permeability assay for high throughput profiling of drug absorption potential. Eur J Med Chem. 2002;37(5):399-407.

33. Skolnik S, Lin X, Wang J, Chen X-H, He T, Zhang B. Towards prediction of in vivo intestinal absorption using a 96-well Caco-2 assay. J Pharm Sci. 2010;99(7):3246-65.

34. Flecainide Acetate Tablet [Product Insert]. Sellersville, PA, Teva Pharmaceuticals USA; 2013.

35. Captapres-TTS [Product Insert]. Ridgefield, CT, Boehringer Ingelheim Pharmaceuticals, Inc.; 2012.

36. Bateman DN. Clinical pharmacokinetics of metoclopramide. Clin Pharmacokinet. 1983;8(6):523-9.
37. Phenazopyridine $\mathrm{HCl}$ [Product Insert]. Coral Springs, FL, Boca Pharmacal, Inc. 2010.

38. Pindolol Tablet [Product Insert]. Morgantown, WV, Mylan Pharmaceuticals Inc. 2010.

39. Tapaninen T, Backman JT, Kurkinen KJ, Neuvonen PJ, Niemi M. Itraconazole, a P-glycoprotein and CYP3A4 inhibitor, markedly raises the plasma concentrations and enhances the renin-inhibiting effect of aliskiren. J Clin Pharmacol. 2011;51(3):359-67.

40. Greenfield RA, Gerber AU, Craig WA. Pharmacokinetics of cefoperazone in patients with normal and impaired hepatic and renal function. Rev Infect Dis. 1983;5 Suppl 1:S127-36.

41. Chuasuwan B, Binjesoh V, Polli JE, Zhang H, Amidon GL, Junginger HE, et al. Biowaiver monographs for immediate release solid oral dosage forms: diclofenac sodium and diclofenac potassium. J Pharm Sci. 2009;98(4):1206-19.

42. Gladziwa U, Klotz U. Pharmacokinetics and pharmacodynamics of H2-receptor antagonists in patients with renal-insufficiency. Clin Pharmacokinet. 1993;24(4):319-32.

43. Food and Drug Administration Center for Drug Evaluation and Research. Application number: 22-350: clinical pharmacology and biopharmaceutics review(s). US FDA website:http:// www.accessdata.fda.gov/drugsatfda_docs/nda/2009/ 022350s000TOC.cfm. 2009. pp 1-127.

44. Spiriva [Product Insert]. Ridgefield, CT, Boehringer Ingelheim Pharmaceuticals, Inc.; 2010.

45. Yang X, Gandhi YA, Duignan DB, Morris ME. Prediction of biliary excretion in rats and humans using molecular weight and quantitative structure-pharmacokinetic relationships. AAPS J. 2009;11(3):511-25.

46. Budha NR, Frymoyer A, Smelick GS, Jin JY, Yago MR, Dresser MJ, et al. Drug absorption interactions between oral targeted anticancer agents and PPIs: is pH-dependent solubility the Achilles heel of targeted therapy? Clin Pharmacol Ther. 2012;92(2):203-13.

47. Garrison KL, Sahin S, Benet LZ. Few drugs display flip-flop pharmacokinetics and these are primarily associated with classes 3 and 4 of the BDDCS. J Pharm Sci. 2015;104(9):3229-35.

48. Sediq A, Kubbinga M, Langguth P, Dressman J. The impact of the EMA change in definition of "dose" on the BCS dosesolubility ratio: a review of the biowaiver monographs. J Pharm Sci. 2014;103(1):65-70.

49. Daousani C, Macheras P. Scientific considerations concerning the EMA change in the definition of "dose" of the BCS-based biowaiver guideline and implications for bioequivalence. Int $\mathbf{J}$ Pharm (Amsterdam, Neth). 2015;478(2):606-9.

50. Varma MV, Steyn SJ, Allerton C, El-Kattan AF. Predicting clearance mechanism in drug discovery: extended clearance classification system (ECCS). Pharm Res. 2015. 